\title{
Petroleum Asphaltenes Part 2 The Effect of Asphaltenes and Resin Constituents on Recovery and Refining Processes
}

\author{
J.G. Speight ${ }^{1}$ \\ 1 CD\&W Inc., 2476 Overland Road, Laramie, Wyoming 82070-4808 - United States \\ e-mail: jamesSp8@aolo.com
}

\begin{abstract}
Résumé - Les asphaltènes, composés pétroliers - Partie 2 : L'effet des asphaltènes et des résines sur les procédés de récupération et de raffinage - Le pétrole est un système complexe en équilibre délicat qui dépend des relations entre ces constituants, relations gouvernées par les interactions moléculaires. Ainsi, des schémas de récupération et de raffinage, en particulier ceux traitant des dépôts asphalténiques (produits de dégradation ou de réaction des asphaltènes et des résines) peuvent être proposés grâce aux connaissances acquises sur la nature des asphaltènes, des résines et de leurs interactions au sein d'un brut.
\end{abstract}

\begin{abstract}
Petroleum Asphaltenes - Part 2: The Effect of Asphaltene and Resin Constituents on Recovery and Refining Processes - Petroleum is a complex but delicately balanced system that depends upon the relationship of the constituent fractions to each other and the relationships are dictated by molecular interactions. Thus, some aspects of recovery and refining chemistry, especially the chemistry of the deposition of asphaltenic material (degradation or reaction products of the asphaltene constituents and the resin constituents), can be proposed by virtue of the studies that have led further knowledge of the nature of asphaltene constituents and the resin constituents and particularly the nature of their interaction in crude oil.
\end{abstract}




\section{PETROLEUM RECOVERY}

The structure and stability of petroleum is based on the manner in which the asphaltene constituents and resin constituents interact. Hence, the disturbance of these interactions plays a role in the formation of sediment and the deposition of asphaltenic material.

Thus, both recovery and refining operations can be affected detrimental when the interactions are disturbed or changed.

The separation of solid sediments from reservoir fluids during oil production is an annoying and frustrating occurrence that can result in the plugging of the formation, well bores, and production facilities and it is necessary to take remedial actions (Park et al., 1994). The separation of asphaltenic (degradation or reaction products of the asphaltene constituents and the resin constituents) sediments during various operations can now be understood, and there is some degree of predictability of phase separation (the separation of a sediment or deposition of asphaltenic material) (Islam, 1994; Park et al., 1994; Speight, 1994, 1999; Andersen and Speight, 2001 and references cited therein). It is the polar (aromatic heteroatom-containing) constituents of petroleum (predominantly the asphaltene constituents and resin constituents) that are responsible for the formation of suspended organic solids during a variety of recovery processes (Islam, 1994; Park et al., 1994).

Petroleum is a delicately balanced system insofar as the different fractions are compatible provided there are no significant disturbances or changes made to the system (Speight, 1999). The changes that can occur which will upset the balance of the petroleum system are:

- alteration of the natural abundances of the different fractions, as might occur when gases are dissolved in the crude oil under reservoir pressure and/or when these dissolved gases are released at the time when a reservoir is first penetrated;

- chemical alteration of the constituents as might occur during recovery processes, especially changes that might be brought on by thermal recovery processes;

- alteration of the distribution of the polar functional groups as might occur during oxidation or the elimination of polar functions during recovery operations, as might occur when exposure of petroleum to air occurs.

When such disturbances occur, it is the higher molecular weight constituents that are most seriously affected. This can lead to incompatibility, which is variously referred to as precipitation, sludge formation, sediment formation and deposition of asphaltenic material, depending on the circumstances. When incompatibility occurs, it is the higher molecular weight polar constituents (the asphaltene constituents and the resin constituents) that form a separate phase as a result of the loss of dispersability. In the reservoir, asphaltene incompatibility can cause blockages of the pores and channels through which the oil must move during recovery operations.

Thus, the dispersability of the higher molecular weight constituents becomes an issue that needs attention. And one of the ways by which this issue can be understood is to be aware of the chemical and physical character of the polar constituents of crude oil. By such means, the issue of dispersability, issue of dispersability, fluid-fluid interactions, oil-rock interactions, and the attending issue of incompatibility can be understood and perhaps predicted.

There are several mechanisms by which asphaltenic material can be discharged (as sediment) from petroleum and cause problems during recovery operations. However, because so little is known about these events that can occur in a reservoir, it is difficult to foresee such events. In fact, there is no general rule that can be applied to the predictability of the separation of asphaltenic sediments. Each crude oil will behave differently under reservoir conditions and, therefore, predictability of behavior is difficult, at best speculative. Any adverse effects on the system can increase the potential for asphaltene incompatibility in the reservoir.

Thus, when a reservoir at the end of a primary depletion period is brought back to operation above the bubble point pressure, as may happen during a water-flooding operation, part of the gas cap formed during blow down will be redissolved in the oil. In some cases, especially when the gas contains substantial amounts of propane and butane, phase separation can occur. This is analogous to the propane and butane deasphalting of a residuum (atmospheric or vacuum) that is employed in the production of asphalt during refinery operations. It is also analogous to the gas deasphalting that can occur during maturation of petroleum in a reservoir (before the reservoir is penetrated and goes into production), when it is believed that dissolution of hydrocarbon gases in the oil can deposit asphaltenic material on the reservoir rock (Evans et al., 1971).

Some enhanced recovery processes can also prompt the separation of sediment. For example, carbon dioxide flooding and miscible hydrocarbon flooding have been known to produce sediments during operations (Islam, 1994). During recovery by carbon dioxide flooding, one or more banks are injected into the reservoir followed by water as the driving fluid. The major operative mechanism in carbon dioxide flooding appears to be swelling of the crude oil, miscibility, viscosity reduction, and most important reduced interfacial tension.

A similar effect can be observed in miscible hydrocarbon flooding during which a rich gas (i.e., a has with a high contact of ethane, propane, butane, etc.) is injected into the reservoir (Islam, 1994). Again, this can approximate the deasphalting process that is used to manufacture asphalt (Speight, 1999) and the injection of the low-boiling hydrocarbon will discharge asphaltenic material from the crude oil. 
Incompatibility is also possible when asphaltene constituents interact with reservoir rock, especially acidic functions of rocks, through the functional groups (e.g. the basic nitrogen species) just as they interact with adsorbents. And, there is the possibility for interaction of the asphaltene with the reservoir rock through the agency of a single functional group in which the remainder of the asphaltene molecule remains in the liquid phase. On the other hand, there is also the possibility that the asphaltene constituents can react with the rock at several points of contact thereby enhancing the bonding to the rock and, in some cases, effecting recovery operations to an even greater extent.

Another area where incompatibility might play a detrimental role during recovery operations is as a result of oxidation. In general, it is the more polar species that oxidize first. And, after incorporation of oxygen to a limit, significant changes can occur in asphaltene molecular weight (Moschopedis and Speight, 1976, 1978). In fact, studies of the oxidation of the constituents fractions of petroleum have also shown that it is the most polar fractions that are more reactive; the less polar constituents are much slower to oxidize (Moschopedis and Speight, 1978). And, the analysis of the products indicates that oxygen is incorporated as polar functions. In addition, the analysis of sediment material produced during recovery operations is consistent with this concept.

It must be emphasized here that the resin constituents incorporate oxygen to produce asphaltene constituents (on the basis of the separation method by which each fraction is defined). The molecular weights of the products are higher than those of the starting materials. This can arise through two phenomena:

- it is the high molecular weight polar species that are oxidized principally;

- the high molecular weight can arise from some association between the product species.

Those recovery processes that involve thermal systems are also susceptible to the deposition of asphaltenic material whether or not the temperature is sufficiently high to cause chemical changes to the petroleum constituents. For example, steam flooding of a reservoir can lead to steam distillation (in the reservoir) of the more volatile constituents of the crude oil. In many cases, it is quite possible that the lower molecular weigh aromatic species might be more volatile in steam that many of the paraffinic constituents of the oil. The overall effect of such a phenomenon is an increase in the paraffinic character of the oil and, hence, precipitation of asphaltenic material. During steam flooding, the precipitated asphaltenic material can be altered or unaltered material.

It is also necessary in any such discussion of the deposition of asphaltenic material to consider the electrical nature of asphaltene constituents. For example, it is known that asphaltene constituents in solution carry an electric charge (Preckshot et al., 1943; Katz and Beu, 1945; Penzes and Speight, 1974). The same may be true of the resin constituents. Indeed, one postulate of asphaltene structure invoked the concept of zwitterions to explain the possibility of charged species within the asphaltene constituents.

Thus, there is the possibility that the induction of charges during the flow of crude oil through pipelines will, under some circumstances, lead to the deposition of asphaltenic material. In other circumstances, such as the use of well stimulation fluids that contain acidic species, there is also the potential to create "salts" of the asphaltenic species (i.e. asphaltene-H+ $\mathrm{X}^{-}$or resin- $\mathrm{H}+\mathrm{X}^{-}$). Whether this be through the agency of the charges species within the asphaltenic molecules or though the agency of the basic (pyridine-type) nitrogen that is know to exist in the rings systems of the asphaltenic constituents is unknown. But it will be sufficient to change the natural order of the constituents within the crude oil leading to the deposition of incompatible (insoluble) material.

In summary, there are several effects that can occur during recovery processes that will lead to the deposition of asphaltenic material. When this happens, problems such as interruption or even cessation of the recovery operations can occur. When the increased popularity of asphaltenecontaining crude oil is taken into consideration, it is surprising that problems of the deposition of asphaltenic material are not more widespread.

\section{THERMAL DECOMPOSITION}

There are various theories relating to the thermal decomposition of organic molecules, and this area of petroleum technology has been the subject of study for several decades (Hurd, 1929; Fabuss et al., 1964; Fitzer et al., 1971). The relative reactivity of asphaltene and resin constituents can be assessed on the basis of bond energies, but the thermal stability of an organic molecule is dependent upon the bond strength of the weakest bond. And even though the use of bond energy data is a method for predicting the reactivity or the stability of specific bonds under designed conditions, the reactivity of a particular bond is also subject to its environment. It is also the stereochemistry of the constituents as they relate to one another that is also of considerable importance. Indeed, the stereochemistry of organic compounds is often a major factor in determining reactivity and properties (Eliel and Wilen, 1994).

Furthermore, the thermal behavior of model compounds may not reflect the true thermal behavior of a complex mixture such as petroleum. The complexity of the individual reactions occurring in an extremely complex mixture and the interference of the products with those from other components of the mixture is unpredictable. Or the interference of secondary and tertiary products with the course of a reaction and, hence, with the formation of primary products may also be cause for concern. Hence, caution is advised when applying the data from model compound studies to the behavior of 


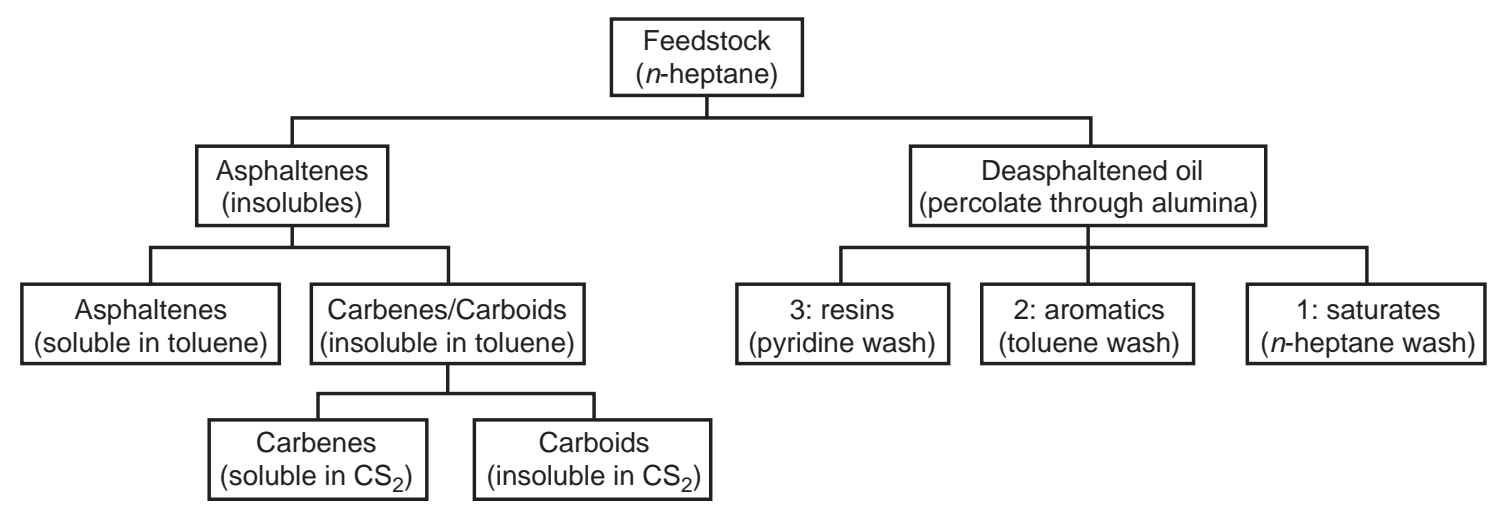

Figure 1

Fractionation of petroleum.

asphaltene and resin constituents. These chemical species have few, if any, parallels in organic chemistry.

Thus, the asphaltene and resin constituents present complex modes of thermal cracking (Tominaga and Kunugi, 1974; Speight, 1999 and references cited therein) and this subject is the focus of this chapter. In fact, it is at this point that the thermal chemistry of model compounds decreases in use in terms of understanding the thermal cracking of petroleum. As stated above, the thermal behavior of model compounds may not (does not) reflect the true thermal behavior of a complex mixture such as petroleum and the thermal cracking of petroleum residua cannot be described by a single activation energy model (Schucker, 1983). The complexity of the individual reactions occurring in a residuum of similar mixture and the interference of the products with those from other components of the mixture is unpredictable. Or the interference of secondary and tertiary products with the course of a reaction and, hence, with the formation of primary products may also be cause for concern. Hence, caution is advised when applying the data from model compound studies to the behavior of petroleum, especially the molecularly complex heavy oils. These have few, if any, parallels in organic chemistry.

Recognition that the thermal behavior of petroleum is related to composition has led to a multiplicity of attempts to establish petroleum and its fractions as compositions of matter. As a result, various analytical techniques have been developed for the identification and quantification of every molecule in the lower boiling fractions of petroleum. However, the name petroleum does not describe a composition of matter but rather a mixture of various organic compounds that includes a wide range of molecular weights and molecular types that exist in balance with each other (Girdler, 1965; Speight, 1994; Long and Speight, 1998).
Thus, investigations of the character of petroleum have focused on the influence of its character in thermal operations and the effect of fractional composition. However, the fractional composition of petroleum varies markedly with the method of isolation or separation, thereby leading to potential complications in the choice of suitable processing schemes for these feedstocks. But, in general, petroleum can be defined (on a relative or standard basis) in terms of three or four general fractions: asphaltene constituents, resins, saturates, and aromatics (Fig. 1).

In a mixture as complex as petroleum, the reaction processes can only be generalized because of difficulties in analyzing not only the products but also the feedstock as well as the intricate and complex nature of the molecules that make up the feedstock. The formation of coke from the asphaltene and resin constituents is detrimental to process efficiency and to catalyst performance (Ternan, 1983; LePage and Davidson, 1986; Speight, 1987; Dolbear, 1998). Although, little has been acknowledged here of the role of low-molecular-weight polar species (resins) in coke formation, the resins are presumed to be lower molecular weight analogs of the asphaltene constituents. This being the case, other than the more facile release of oxygen entities from the resin constituents, similar reaction pathways apply (Moschopedis et al., 1978; Posadov et al., 1977, 1978; Parkash et al., 1980).

The asphaltene and resin constituents generally produce coke in yields varying from almost twenty five per cent by weight to more than sixty per cent by weight (Fig. 2) (Speight, 1999 and references cited therein). However, the focus of thermal studies has been, for obvious reasons, on the asphaltene constituents, which produce thermal coke in amounts varying from approximately 35 to approximately $65 \mathrm{wt} \%$. Petroleum mapping techniques often show the 
asphaltene and resin constituents producing coke while the volatile constituents produce distillates. It is often ignored that the asphaltene constituents also produce high yields (35 to $65 \mathrm{wt} \%$ ) of volatile thermal products which vary from condensable liquids to gases.



Figure 2

Range of carbon residue yields for different fractions.

Because of the propensity of the resin and asphaltene fractions to produce high yields ( 30 to $60 \%$ by weight) of thermal coke, the thermal decomposition of petroleum asphaltene constituents has naturally received the considerable attention (Girdler, 1965; Magaril and Aksenova, 1967, 1970a, 1970b; Magaril and Ramazaeva, 1969; Magaril et al., 1970, 1971; Gimaev et al., 1980; Sabanenkov, et al., 1980; Schucker and Keweshan, 1980; Shiroto et al., 1983; Speight, 1987). Special attention has been given to the nature of the volatile products of asphaltene decomposition mainly because of the difficulty of characterizing the nonvolatile coke.

During the thermal decomposition of asphaltene constituents, the majority of the organic nitrogen, sulfur, and metallic constituents (Reynolds, 1998) originally in the asphaltene constituents invariably concentrate in the nonvolatile coke, even acting as chemical initiators to coke formation (Vercier, 1981; Speight, 1989). The chemistry of asphaltene coking has been suggested to involve the thermolysis of thermally labile bonds to form reactive species that them react with each other (condensation) to form coke. In addition, the highly aromatic and highly polar heteroatomcontaining products separate from the surrounding oil medium as an insoluble phase and proceed to form coke.

It has been generally assumed that the thermal chemistry of coke formation involves immediate condensation reactions to produce higher molecular weight, condensed aromatic species. However, the initial reactions in the coking of petroleum that contains resin and asphaltene constituents involves the thermolysis of aromatic-alkyl systems to produce volatile species (paraffins and olefins) and nonvolatile species (aromatics) leading to a relationship between asphaltene constituents content and carbon residue formation (Speight, 1987; Roberts, 1989; Schabron and Speight, 1997).

Thermal cracking of model compounds confirm that volatility of the fragments is a major influence in carbon residue formation. Indeed, the formation of a coke-like substance during thermal decomposition of aromatic compounds and related heterocyclic compounds are dependent upon the structure, and hence the volatility, of the polynuclear aromatic hydrocarbon but more specifically on:

- the degree of polynuclear condensation in petroleum;

- the average number of alkyl groups on the polynuclear aromatic systems;

- the occurrence of heteroatoms in the ring;

- the type of heteroatom (Madison and Roberts, 1958; Lewis and Edstrom, 1963; Lewis and Singer, 1964, 1967; Lewis, 1980, 1982).

Nitrogen species also appear to contribute to the pattern of the thermal cracking. For example, the hydrogen or carboncarbon bonds to adjacent to ring nitrogen undergo thermolysis quite readily, as if promoted by the presence of the nitrogen atom (Fitzer et al., 1971; Speight, 1987). If it can be assumed that heterocyclic nitrogen plays a similar role in the thermolysis of resin and asphaltene constituents, the initial reactions therefore involve thermolysis of aromatic-alkyl bonds that are enhanced by the presence of heterocyclic nitrogen. An ensuing series of secondary reactions, such as aromatization of naphthenic species and condensation of the aromatic ring systems, then leads to the production of coke. Thus, the initial step in the formation of coke from resin and asphaltene constituents is the formation of volatile hydrocarbon fragments and nonvolatile heteroatom-containing systems. The latter products are undoubtedly insoluble (Bjorseth, 1983; Dias, 1987, 1988) in the surrounding hydrocarbon medium and the next step is gradual carbonization of such entities to form coke (Magaril and Aksenova, 1967; Magaril and Ramzaeva, 1969; Magaril et al., 1970; Cooper and Ballard, 1962).

Thus, the challenges facing process chemistry and physics are determining:

- the means by which petroleum constituents thermally decompose;

- the nature of the products of thermal decomposition;

- the subsequent decomposition of the primary thermal products;

- the interaction of the products with each other;

- the interaction of the products with the original constituents;

- the influence of the products on the composition of the liquids. 
Several chemical models (Wiehe, 1993 and references cited therein; Gray, 1994 and references cited therein; Speight, 1994 and references cited therein) describe the thermal decomposition of asphaltene constituents and, by inference, the constituents of the resin fraction. The prevalent thinking is that the polynuclear aromatic fragments become progressively more polar as the paraffinic fragments are stripped from the ring systems by scission of the bonds (preferentially) between the carbon atoms alpha and beta to the aromatic rings.

The polynuclear aromatic systems that have been denuded of the attendant hydrocarbon moieties are somewhat less soluble in the surrounding hydrocarbon medium than their parent systems (Bjorseth, 1983; Dias, 1987, 1988). Two factors are operative in determining the solubility of the polynuclear aromatic systems in the liquid product. The alkyl moieties that have a solubilizing effect have been removed and there is also enrichment of the liquid medium in paraffinic constituents. Again, there is an analogy with the deasphalting process except that the paraffinic material is a product of the thermal decomposition of the asphaltene molecules and is formed in situ rather than being added separately.

The coke has a lower hydrogen-to-carbon atomic ratio than the hydrogen-to-carbon ratio of any of the constituents present in the original crude oil. The hydrocarbon products may have a higher hydrogen-to-carbon atomic ratio than the hydrogen-to-carbon ratio of any of the constituents present in the original crude oil or hydrogen-to-carbon atomic ratios at least equal to those of many of the original constituents. It must also be recognized that the production of coke and volatile hydrocarbon products is accompanied by a shift in the hydrogen distribution (Speight, 1999).

The initial stages of the thermal decomposition of asphaltene constituents have been least well understood of the thermal decomposition process. It is known that the overall thermal decomposition involves scission of carbon-carbon bonds, aromatization of naphthenic ring systems, formation of lower molecular weight material, and formation of coke. The presence of hydrogen during the thermal decomposition of asphaltene constituents can alter the product slate. However the chemistry remains complex and representation of the chemistry of asphaltene thermolysis is speculative and has been done simply by the use of nonchemical formulae (Speight, 1999).

If no side reactions occur, very residence long times at low temperature should be equivalent to very short times at high temperature. Thermal reactions, however, can give rise to a variety of different reactions, so that selectivity for a given product changes with temperature and pressure. In fact, the nature of the thermal processes varies considerably.

The formation of solid sediments, or coke, during thermal processes is a major limitation on processing. Furthermore, the presence of different types of solids shows that solubility controls the formation of solids. And the tendency for solid formation changes in response to the relative amounts of the light ends, middle distillates, and residues and to changing chemical composition during the process (Gray, 1994). In fact, the prime mover in the formation of incompatible products during the processing of feedstocks containing asphaltene constituents is the nature of the primary thermal decomposition products, particularly those designated as carbenes and carboids (Fig. 1) (Speight, 1987, 1992; Wiehe, 1992, 1993).

One of the postulates of coke formation involves the production of coke by a sequence of polymerization and condensation steps from the lower molecular weight constituents to the higher molecular weight constituents. Whilst this concept is acceptable for pure aromatic hydrocarbons (Lewis, 1980, 1982), the formation of coke by thermal cracking the constituents of petroleum asphaltene constituents requires a modification of this concept. Indeed, present evidence (Wiehe, 1992, 1993; Speight, 1994, 1999) shows that the reaction pathway of the asphaltene constituents to coke is much more complex and involves at least several reaction stages.

Several kinetic studies have concentrated on the conversion of the asphaltene portion of petroleum residua. One in particular (Schucker and Keweshan, 1980) showed that asphaltene constituents exhibit a coke induction period when thermally converted at $400^{\circ} \mathrm{C}$. Other workers (Savage et al., 1988) also observed a coke-induction period for the thermolysis of asphaltene constituents that disappeared when the thermolysis temperature was raised to $450^{\circ} \mathrm{C}$. It was proposed (Savage and Klein, 1989) that toluene-insoluble coke could be defined as a molecular species with a molecular weight of greater than 300 and a hydrogen-to-carbon atomic ratio less than 1 .

Several features of the reaction have led to the postulation that coke formation is triggered by the phase separation of asphaltene constituents (and that addition of oil retarded phase separation and, hence, the rate of coke formation) from which current models have been developed to include the four common features of thermal cracking mechanisms including:

- concentration of the highly reactive heteroatom compounds in the coke precursors;

- an induction period prior to coke formation;

- a maximum concentration of asphaltene constituents in the reacting liquid;

- a decrease in the asphaltene concentration that parallels the decrease in heptane-soluble material (Levinter et al., 1966a, 1966b; Levinter and Medvedeva, 1967; Magaril and Aksenova, 1967, 1968, 1970a, 1970b, 1972 ; Magaril et al., 1971; Valyavin et al., 1979; Vercier, 1981; Speight, 1987; Takatsuka et al., 1989; Speight, 1989; Wiehe, 1992, 1993).

Thus, a model for the thermal cracking of the asphaltene and resin constituents has been proposed in which the scission of alkyl side chains occurs thereby leaving a polar core 
of reduced volatility that commences to produce a carbon residue (Speight, 1994; Wiehe, 1994). The maximum solubility of the thermal products and asphaltene constituents is proportional to the total heptane-soluble materials, as suggested by the observation that the decrease in asphaltene constituents parallels the decrease of heptane-soluble materials. Finally, the conversion of the insoluble product asphaltene constituents into toluene-insoluble coke is pictured as producing a heptane-soluble by-product, which provides a mechanism for the heptane-soluble conversion to deviate from first-order behavior once coke begins to form. An infinite reaction rate for this coke-forming reaction is used to show that the reaction rate is phase equilibrium controlled:

$$
\begin{array}{ll}
\mathrm{H}^{+}=a \mathrm{~A}^{*}+(1-a) \mathrm{V} & \text { reaction constant } k_{\mathrm{H}} \\
\mathrm{A}+=m \mathrm{~A}^{*}+n \mathrm{H}^{*}+(1-m-n) \mathrm{V} & \text { reaction constant } k_{\mathrm{A}} \\
\text { solubility limit: } \mathrm{A}_{\text {max }}^{*}=S_{\mathrm{L}}\left(\mathrm{H}^{+}+\mathrm{H}^{*}\right) & \\
\mathrm{A}^{*}{ }_{\mathrm{ex}}=\mathrm{A}^{*}-\mathrm{A}_{\text {max }}^{*} & \\
\mathrm{~A}^{*}{ }_{\text {ex }}=(1-y) \mathrm{TI}+y \mathrm{H}^{*} &
\end{array}
$$

where:

$a \quad$ is a stoichiometric coefficient;

$\mathrm{A}^{+} \quad$ reactant asphaltene constituents;

A* asphaltene cores;

$\mathrm{A}^{*}{ }_{\max }$ maximum asphaltene cores that can be held in solution;

$\mathrm{A}^{*}{ }_{\mathrm{ex}} \quad$ excess asphaltene cores beyond what can be held in solution;

$\mathrm{H}^{+} \quad$ reactant, nonvolatile heptane-soluble materials;

$\mathrm{H}^{*} \quad$ product, nonvolatile heptane-soluble materials;

$k_{\mathrm{A}} \quad$ first-order reaction rate constant for reactant asphaltene thermolysis $\left(\mathrm{min}^{-1}\right)$;

$k_{\mathrm{H}} \quad$ first-order reaction rate constant for the thermolysis of reactant heptane-soluble materials $\left(\mathrm{min}^{-1}\right)$;

$m \quad$ stoichiometric coefficient;

$n \quad$ stoichiometric coefficient;

$S_{\mathrm{L}}, \quad$ solubility limit (wt $\% / \mathrm{wt} \%$ );

TI toluene-insoluble coke;

$\mathrm{V} \quad$ volatile materials.

The first two parallel first-order reactions for the thermolysis of unreacted heptane-soluble materials and unreacted asphaltene constituents are the only reactions that occur during the coke induction period. During the coke induction period, the reactant asphaltene constituents form only lower molecular weight products and, as long as the asphaltene constituents remain dissolved, the heptane-soluble materials can provide sufficient abstractable hydrogen to terminate asphaltene free radicals, making asphaltene radical-asphaltene radical recombination infrequent.

As the conversion proceeds, the concentration of reacted resin and asphaltene molecular cores continues to increase and

the heptane-soluble fraction continues to decrease until the solubility limit, $S_{\mathrm{L}}$ is reached. Beyond the solubility limit, the excess asphaltene cores, $\mathrm{A}^{*}{ }_{\mathrm{ex}}$, phase separate to form a second liquid phase that is lean in abstractable hydrogen. In this new phase asphaltene radical-asphaltene radical recombination is quite frequent, causing a rapid reaction to form solid coke and a by-product of a heptane-soluble core. After the phase separation step, the formation of coke during the thermal decomposition of petroleum can then follow the mechanism postulated form aromatic hydrocarbons (Lewis, 1980, 1982), in which the separated reacted asphaltene constituents (carbenes) and carboids) react together to produce coke.

Similar mathematical relationships can be derived for the thermal decomposition of the resin constituents in which decomposition is presumed (but not proven) to involve the formation of an asphaltene-type intermediate product as an additional first step. Coke formation ensues after the formation of such a product. However, there is no reason to discount the concept that coke-like precursors (analogous to those produced thermally from asphaltene constituents) cannot form by the initial thermolysis of the resin constituents.

Previously, it was demonstrated (Schucker and Keweshan, 1980; Savage et al., 1988) that the hydrogen-to-carbon atomic ratio of the asphaltene constituents decreases rapidly with reaction time for asphaltene thermolysis and then approaches an asymptotic limit at long reaction times, which provides qualitative evidence for asphaltene cracking down to a core.

These findings offer some indication of the proposed chemistry of coke or sediment formation during petroleum processing. However, in each case the aromatization of naphthene rings and the potential/reality of cyclodehydrogenation are ignored. In addition, the thermal reactions of he resin constituents are not addressed. The asphaltene constituents rely upon the resins constituents for stability within the oil medium (Koots and Speight, 1975). Removal or thermal alteration of the resin constituents, through the more facile elimination of oxygen functions (Moschopedis et al., 1978; Parkash et al., 1980), will also cause the asphaltene constituents to separate as a distinct phase. Such processes would also lead to increased aromaticity of the polynuclear aromatic-naphthenic (often referenced as redistribution of hydrogen within constituents) core and further enhance the insolubility (phase separation) of the dealkylated polynuclear product.

The available data suggest that the thermal cracking of the asphaltene and resin constituents (leading to the formation of volatile products and coke) is a complex process involving both chemical reactions and thermodynamic behavior. Reactions that contribute to this process are cracking of side chains from aromatic groups. dehydrogenation of naphthenes to form aromatics, condensation of aliphatic structures to form aromatics, condensation of aromatics to form higher fused-ring aromatics, and dimerization or oligomerization 


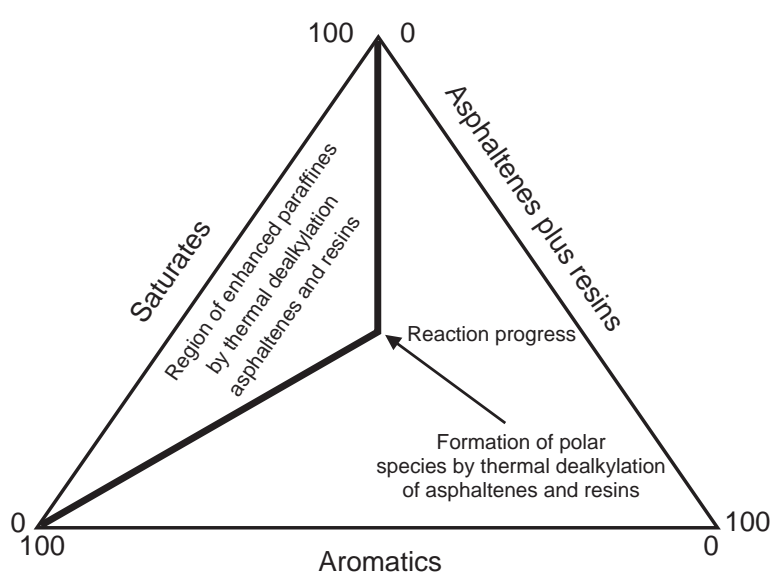

Figure 3

Phase relationships and changes during thermal cracking.

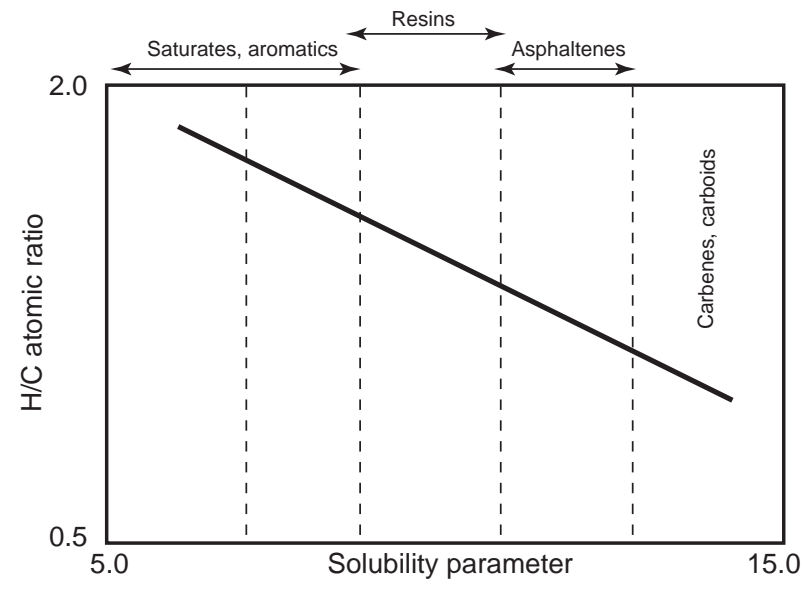

Figure 4

Relationship between $\mathrm{H} / \mathrm{C}$ atomic ratio and solubility parameter. reactions. Loss of side chains always accompanies thermal cracking, and dehydrogenation and condensation reactions are favored by hydrogen deficient conditions.

The importance of the use of solvents to mitigate coke formation during the thermal decomposition of petroleum has been recognized for many years (Carlson et al., 1958; Langer et al., 1961, 1962; Hill et al., 1968), but their effects have been correctly ascribed to hydrogen donor reactions that have an inhibiting effect on the formation of the molecular species that are prone to phase separation. The separation of the phases depends on the solvent characteristics of the liquid. Addition of aromatic solvents suppresses phase separation, whereas paraffins enhance separation. Microscopic examination of coke particles often shows evidence for mesophase, spherical domains that exhibit the anisotropic optical characteristics of liquid crystals.

The phase separation phenomenon (Fig. 3) that is the prelude to coke formation can also be explained by use of the solubility parameter $(\delta)$ (Fig. 4) for petroleum fractions and for the solvents (Small, 1953; Hansen, 1969; Mitchell and Speight, 1973; Barton, 1975; Speight, 1992, 1994). Although little is known about the solubility parameter of petroleum fractions, there has been a noteworthy attempt to define the solubility parameter ranges for different fossil fuel liquids (Yen, 1984; Speight, 1994, 1999).

Thus, the solubility parameter of asphaltene constituents can be estimated to fall in the range 9 to 12 , which is in keeping with the asphaltene constituents being composed of a mixture of different compound types with an accompanying variation in polarity. Removal of alkyl side chains from the asphaltene constituents decreases the hydrogen-to-carbon atomic ratio (Wiehe, 1993; Gray, 1994; Speight, 1999 and references cited therein) and increases the solubility parameter thereby bringing about a concurrent decrease of the asphaltene product in the hydrocarbon solvent.

When catalytic processes are employed, complex molecules (such as those that may be found in the original resin fraction and in the original asphaltene fraction) or those formed during the process, are not sufficiently mobile (or are too strongly adsorbed by the catalyst) to be saturated by the hydrogenation components. Hence, these molecular species continue to condense and eventually degrade to coke. These deposits deactivate the catalyst sites and eventually interfere with the process.

Several noteworthy attempts have been made to focus attention on the asphaltene constituents during hydroprocessing studies. The focus has been on the macromolecular changes that occur by investigation of the changes in the generic fractions, i.e., the asphaltene constituents, the resins, and the other fractions that make up such a feedstock (Drushel, 1972).

This option suggests that the overall pathway by which hydrotreating and hydrocracking of heavy oils and residua occur involves a stepwise mechanism:

$$
\begin{gathered}
\text { Asphaltene constituents } \rightarrow \text { polar aromatics } \\
\text { (resin-type components) } \\
\text { Polar aromatics } \rightarrow \text { aromatics } \\
\text { Aromatics } \rightarrow \text { saturates }
\end{gathered}
$$

A direct step from either the asphaltene constituents or the resin-type components to the saturates is not considered a predominant pathway for hydroprocessing.

In summary, and as these concepts show, characterization data can be used as an integral part of understanding the thermal chemistry of asphaltene constituents as a start in predicting product yield and product distribution; predictions of product quality will follow. 


\section{REFERENCES}

Andersen, S.I. and Speight, J.G. (2001) Petroleum Science and Technology, 19, 1.

Barton, A.F.M. (1975) Chem. Revs., 75, 731-753.

Bjorseth, A. (1983) Handbook of Polycyclic Aromatic Hydrocarbons, Marcel Dekker Inc., New York.

Carlson, C.S., Langer, A.W., Stewart, J. and Hill, R.M. (1958) Ind. Eng. Chem., 50, 1067-1070.

Cooper, T.A. and Ballard, W.P. (1962) Thermal Cracking, Visbreaking, and Thermal Reforming. Advances in Petroleum Chemistry and Refining, K.A. Kobe and J.J. McKetta (eds.), VI, Chapter 4, 170-239, Interscience, New York.

Dias, J.R. (1987) Handbook of Polycyclic Hydrocarbons. Part A. Benzenoid Hydrocarbons, Elsevier, New York.

Dias, J.R. (1988) Handbook of Polycyclic Hydrocarbons. Part B. Polycyclic Isomers and Heteroatom Analogs of Benzenoid Hydrocarbons, Elsevier, New York.

Dolbear, G.E. (1998) Hydrocracking: Reactions, Catalysts, and Processes. Petroleum Chemistry and Refining. J.G. Speight (ed.), Chapter 7, Taylor \& Francis Publishers, Washington, DC..

Drushel, H.V. (1972) Preprints, Div. Petrol. Chem. Am. Chem. Soc., 17, 4, F92.

Eliel, E. and Wilen, S. (1994) Stereochemistry of Organic Compounds, John Wiley \& Sons Inc., New York.

Evans, C.R., Rogers, M.A., and Bailey, N.J.L. (1971) Chem. Geol, 8, 147.

Fabuss, B.M., Smith, J.O. and Satterfield, C.N. (1964) Thermal Cracking of Pure Saturated Hydrocarbons. Advances in Petroleum Chemistry and Refining, IX, Chapter 4, 156-210.

Fitzer, E., Mueller, K. and Schaefer, W. (1971) The Chemistry of the Pyrolytic Conversion of Organic Compounds to Carbon. The Chemistry and Physics of Carbon, 7, 237.

Gimaev, R.N., Gubaidullin, V.Z., Rogacheva, O.V., Davydov, G.F. and Danil'yan, T.D. (1980) Khim. Tekhnol. Topl. Masel., 16, 3, 42-45.

Girdler, R.B. (1965) Proc. Assoc. Asphalt Paving Technologists, 34, 45-79.

Gray, M.R. (1994) Upgrading Petroleum Residues and Heavy Oils, Marcel Dekker Inc., New York.

Hansen, C.M. (1969) Ind. Eng Chem. Product Research and Development, 8, 1, 2-11.

Hill, J.C., Engelbrecht, R.M., Moore, R.N., and Spillane, L.J. (1968) Preprints, Div. Petrol. Chem. Am. Chem. Soc., 13, 3, 183.

Hurd, C.D. (1929) The Pyrolysis of Carbon Compounds, The Chemical Catalog Company Inc., New York.

Islam, M.R. (1994) In: Asphaltene constituents and Asphalts, 1. Developments in Petroleum Science. Chapter 11, 40. Elsevier, Amsterdam..

Katz, D.L. and Beu, K.E. (1945) Ind. Eng. Chem., 43, 1165.

Koots, J.A. and Speight, J.G. (1975) Fuel, 54, 179.

Langer, A.W., Stewart, J., Thompson, C.E., White, H.T. and Hill, R.M. (1961) Ind. Eng. Chem., 53, 27-30.

Langer, A.W., Stewart, J., Thompson, C.E., White, H.T., and Hill, R.M. (1962) Ind. Eng. Chem. Process Design and Development, 1, 309-312.

LePage, J.F., and Davidson, M. (1986) Rev. de l'Institut Français du Pétrole, 41, 131- 143.

Levinter, M.E., and Medvedeva, M.I. (1967) Tekhnol. Topl. Masel, 12, 4, 20-22.
Levinter, M.E., Galiakbarov, M.F., Panchenkov, G.M., Aseev, Yu. G., Nedoshivin, Yu N., Kinkelshtein, G.B. and Medvedeva M.I. (1966a) Khim. Tekhol. Topliv. Masel., 11, 9, 31-35.

Levinter, M.E., Medvedeva, M.I., Panchenkov, G.M., Agapov. G.I. (1966b) Khim. Tekhol. Topliv. Masel. 11, 11, $25-27$.

Lewis, I.C. (1980) Carbon, 18, 191-196.

Lewis, I.C. (1982) Carbon, 20, 519-529.

Lewis, I.C. and Edstrom, T. (1963) J. Org. Chem., 28, 20502057.

Lewis, I.C. and Singer, L.S. (1964) Carbon, 2, 115-122.

Lewis, I.C. and Singer, L.S. (1967) Carbon, 5, 373-381.

Long, R.B. and Speight, J.G. (1998) The Composition of Petroleum. Petroleum Chemistry and Refining, Chapter 1, J.G Speight (ed), Taylor \& Francis Publishers, Washington, DC.

Madison, J.J., and Roberts, R.M. (1958) Ind. Eng. Chem., 50, 237-250.

Magaril, R.Z. and Aksenova, E.L. (1967) Izv. Vyssh. Zaved. Neft Gaz, 10, 11, 134-136.

Magaril, R.Z. and Aksenova, E.L. (1968) Int. Chem. Eng., 8, 4, 727-729.

Magaril, R.Z. and Ramazaeva, L.F. (1969) Izv. Vyssh. Ucheb. Zaved. Neft Gaz, 12, 1, 61-64.

Magaril, R.Z. and Aksenova, E.I. (1970a) Khim. Izv. Vyssh. Ucheb. Zaved. Neft Gaz, 13, 5, 47-53.

Magaril, R.Z. and Aksenova, E.I. (1970b) Khim. Tekhnol. Topl. Masel, 15, 7, 22-24.

Magaril, R.Z., Ramazaeva, L.F. and Askenova, E.I. (1970) Khim. Tekhnol. Topliv Masel, 15, 3, 15-16.

Magaril, R.Z., Ramazeava, L.F. and Aksenova, E.I. (1971) Int. Chem. Eng., 11, 250.

Magaril, R.Z., and Aksenova, E.I. (1972) Khim. Tekhnol. Tr. Tyumen. Ind. Inst., p. 169-172.

Mitchell, D.L. and Speight, J.G. (1973) Fuel, 52, 149.

Mohanty, S., Kunzru, D. and Saraf, D.N. (1990) Fuel, 69, 14671473.

Moschopedis, S.E., and Speight, J.G. (1976) Proc. Assoc. Paving Technol., 45, 78 .

Moschopedis, S.E., and Speight, J.G. (1978) Fuel, 57, 239.

Moschopedis, S.E., Parkash, S., and Speight, J.G. (1978) Fuel, 57, 431 .

Park, S.J., Escobedo, J. and Mansoori, G.A. (1994) In: Asphaltene Constituents and Asphalts, 1. Developments in Petroleum Science. Chapter 8, 40. T.F. Yen and G.V. Chilingarian (eds.), Elsevier, Amsterdam..

Penzes, S. and Speight, J.G. (1974) Fuel, 53,192.

Parkash, S., Moschopedis, S.E. and Speight, J.G. (1980) Fuel, 59, 64 .

Posadov, I.A., Pokonova, Yu.V., Popov, O.G., and Proskuryakov, V.A. (1977) Zhur. Prikl. Kim., 50,1578-1580.

Posadov, I.A., Popov, O.G. and Proskuryakov, V.A. (1978) Zhur. Prikl. Kim., 51, 2113-2114.

Preckshot, G.W., Delisle, N.G., Cottrell, C.E., and Katz, D.L. (1943) AIME Trans., 151, 188.

Reynolds, J.G. (1998) Metals and Heteroelements. In: Heavy Crude Oils. Petroleum Chemistry and Refining, Chapter 3, J.G. Speight (ed.), Taylor \& Francis Publishers, Washington, DC..

Roberts, I. (1989) Preprints, Div. Petrol. Chem. Am. Chem. Soc., 34, 2, 251. 
Sabanenkov, S.A., Morozova, L.A. and Syunyaev, Z.I. (1980) Chim. Tekhnol. Fuels and Oils, 16, 3-4, 204-207.

Savage, P.E. and Klein, M.T. (1989) Chem. Eng. Sci., 44, 393.

Savage, P.E., Klein, M.T. and Kukes, S.G. (1988) Energy \& Fuels, 2, 619-628.

Schabron, J.F. and Speight, J.G. (1997) Revuede l' Institut Français du Pétrole, 52, 73.

Schucker, R.C. (1983) Ind. Eng. Chem. Process Design and Development, 22, 615-619.

Schucker, R.C. and Keweshan, C.F. (1980) Preprints, Div. Fuel Chem. Am. Chem. Soc., 25, 155.

Shiroto, Y., Nakata, S., Fukul, Y. and Takeuchi, C. (1983) Ind. Eng. Chem. Process Design and Development, 22, 248-257.

Small, P.A. (1953) J. Appl. Chem., 3, 2, 71-80.

Speight, J.G. (1987) Preprints, Div. Petrol. Chem. Am. Chem. Soc., 32, 2, 413.

Speight, J.G. (1989) Neftekhimiya, 29, 732.

Speight, J.G. (1992) 4th International Conference on the Stability and Handling of Liquid Fuels, Proceedings. US. Department of Energy (DOE/CONF-911102). p. 169.

Speight, J.G. (1994) Chemical and Physical Studies of Petroleum Asphaltene constituents. In: Asphalts and Asphaltene
Constituents, 1, Chapter 2, T.F. Yen and G.V. Chilingarian (eds.), Elsevier, Amsterdam, The Netherlands.

Speight, J.G. (1998) Thermal Chemistry of Petroleum Constituents. In: Petroleum Chemistry and Refining, Chapter 5, J.G. Speight (ed.), Taylor \& Francis Publishers, Washington, DC.

Speight, J.G. (1999) The Chemistry and Technology of Petroleum, $3^{\text {rd }}$ Edition, Marcel Dekker Inc., New York.

Takatsuka, T., Kajiyama, R., Hashimoto, H., Matsuo, I. and Miwa, S.A. (1989) J. Chem. Eng. Japan, 22, 304.

Ternan, M. (1983) Can. J. Chem. Eng., 61, 133.

Tominaga, H. and Kunugi, T. (1974) Int. Chem. Eng., 14, 753768.

Vercier, P. (1981) The Chemistry of Asphaltene Constituents. In: Advances in Chemistry Series No. 195, J.W. Bunger and N.C. Li (eds), American Chemical Society, Washington, DC.

Wiehe, I.A. (1992) Ind. Eng. Chem. Res., 31, 530-536.

Wiehe, I.A. (1993) Ind. Eng. Chem. Research, 32, 2447-2554.

Wiehe, I.A. (1994) Energy \& Fuels, 8, 536-544.

Yen, T.F. (1984) In: The Future of Heavy Crude Oil and Tar Sands, R.F. Meyer, J.C. Wynn, and J.C. Olson (eds.), McGrawHill, New York.

Final manuscript received in October 2004 